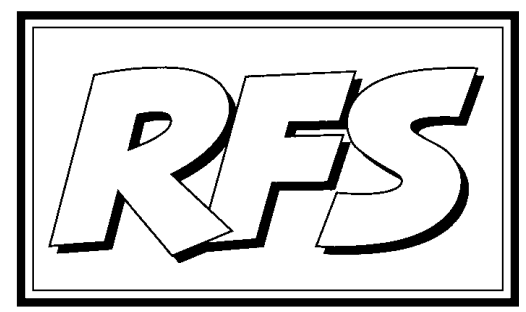

Revista de Fomento Social, 55 (2000), 521-538

\title{
Tres tareas de fondo ante los problemas de la justicia hoy
}

Complemento a la ponencia de Luis de Sebastián

La lectura de la ponencia de Luis de Sebastián puede provocar distintas reacciones en el lector. Las más peligrosas serían, a mi entender, dos. Sería peligroso, en primer lugar, que nos sintiéramos impotentes ante problemas de tanta envergadura; y sería igualmente peligroso que renunciáramos incluso a comprender las cuestiones de que se nos habla en ella. Ambas reacciones tendrían un efecto semejante: que nos desentendiéramos de to do eso, que quedáramos como desactivados en relación con la problemática global de nuestra época. Es el recurso de tantos que se refugian en su mundo privado y prescinden de esa otra realidad a la que consideran inabarcable.

Yo desearía contribuir con este comentario a combatir esas posibles tentaciones de huida, invitándoles más bien a implicarse en toda esa panorámica que se nos ha trazado. Y para ello no voy a volver directamente sobre

* Profesor de la Facultad de Teología de Granada y de la Facultad de Ciencias Económicas y Empresariales - ETEA, de Córdoba. 
Ios problemas expuestos. Voy a buscar, más bien, algunos implícitos que anidan en el fondo de ellos. Más bien, los llamaría tareas que se nos plantean a la vista de todo lo oído.

\section{1atarea: comprender la globalización en todas sus dimensiones y compren- der la ideología que le sirve de legitimación}

Encontré no hace mucho tiempo una definición de globalización que me resultó sugerente y esclarecedora en su simplicidad: la globalización como la presencia del mundo entero en nuestras vidas ${ }^{1}$. Creo que es sugerente porque conecta con la experiencia cotidiana de cualquier persona, aunque muchas veces no sea consciente de ello. Basta salir a la calle y entrar en unos grandes almacenes para constatar que se nos ofrecen productos fabricados en los países más diferentes. Y no hace falta salir a la calle: es suficiente conectar la televisión para entrar en contacto con los lugares más remotos. Pero la experiencia más fuerte de esta globalización cotidiana la tenemos en internet, que reduce de forma tan espectacular las distancias espaciales y temporales...

Ahora bien, esta definición resulta demasiado sencilla. Si se quiere ahondar más en el fenómeno cabría recurrir a otra más técnica. Por ejemplo, ésta: globalización es un proceso dinámico de creciente libertad e integración mundial de los mercados de trabajo, bienes, servicios, tecnología y capitales ${ }^{2}$.

Así entendida, la globalización es, ante todo, un fenómeno económico. Se puede aceptar este enfoque como punto de partida, subrayando al mismo tiempo que estamos ante un proceso que viene de lejos. Sus orígenes históricos hay que buscarlos en el desarrollo mismo del capitalismo y de la economía moderna: por consiguiente, al menos desde comienzos del siglo XIX. En estos dos siglos el proceso ha ido avanzando geográficamente y profundizando en su alcance. Y este avance, que progresó de forma cuantitativa durante mucho tiempo, ha llegado a producir hoy un cambio cualitativo. Tal cambio cualitativo es el que justifica el uso de un nuevo término: globalización o mundialización (el primero de origen anglosajón y el segundo propuesto por los franceses).

Quizás la manifestación más elocuente de este cambio cualitativo es que

1 Commission Justice et Paix - France, Maîtriser la mondialisation (mars 1999), Documentation Catholique 81 (1999) 330.

2 Cf. G. DE LA DeheSA, Comprender la globalización, Madrid, Alianza, 2000, 17. 
el mercado nacional deja de ser el principal marco de referencia de la actividad económica para ceder su lugar al mercado mundial. A la hora de planificar la producción o la colocación de los productos terminados, son muchas las empresas que ya no se atienen preferentemente al mercado nacional, con sus restricciones y sus oportunidades, sino que actúan desde las crecientes posibilidades que ofrece todo el planeta, gracias a las facilidades para las comunicaciones, para los transportes y para las relaciones económicas de todo tipo.

Otra de las manifestaciones de que estamos ante un cambio cualitativo es que la globalización ha desbordado el ámbito económico y se ha convertido en un fenómeno cultural: en este sentido afecta a los usos y costumbres, al sistema de valores omnipresente por encima de las diferencias culturales que diferencian a los pueblos. Eseestilo devida-de matriz occidental y, más concretamente, norteamericana- lucha por imponerse con la ayuda inestimable de unos poderosos medios de comunicación imbuidos de la lógica del mercado.

Pero, más que hacer un estudio en profundidad del fenómeno de la globalización, mi intención aquí es descubrir la tarea que este hecho dominante nos impone. Y ello pasa por hacer una evaluación ética de la misma.

Me valdré para ello de los últimos informes anuales del Programa de Naciones Unidas para el Desarrollo. En el de 1997 tomaba distancia crítica contra las recetas liberalizadoras a ultranza, que facilitan los procesos globalizadores:

La receta consiste en liberalizar los mercados nacionales y mundiales en la creencia de que las corrientes libres de comercio, finanzas e información producirán el mejor resultado para el crecimiento del bienestar humano. Todo se presenta con un aire de inevitabilidad y convicción abrumadora. Desde el auge del libre comercio en el siglo XIX no había una teoría económica que concitara una certidumbre tan generalizada 3 .

A renglón seguido se denuncia que esta globalización no es homogénea porque la liberalización se aplica de forma muy discriminatoria. Los dos ejemplos que se aducen (la mano de obra sin calificar, los productos agrícolas y textiles) son muy ilustrativos:

Los principios de los mercados mundiales libres, sin embargo, se aplican de manera selectiva. Si así no fuera, el mercado mundial de mano de obra sin calificar sería tan libre como el mercado de las exportaciones o los capitales de los países industrializados. Las negociaciones mundiales avanzan rápidamente hacia un mercado mundial

3 Programa de las naciones Unidas para el Desarrollo, Informe sobre desarrollo humano 1997. Desarrollo humano para erradicar la pobreza, Nueva York - Madrid 1997, 92 
libre en inversiones y servicios extranjeros. Pero la intervención en la agricultura y los textiles sigue siendo elevada, lo que constituye un obstáculo para los países en desarrollo. Carentes de poder, con demasiada frecuencia se descuidan y socavan los intereses de los países pobres y de los pueblos pobres ${ }^{4}$.

Dicho con otras palabras: la globalización es selectiva porque no se hace al mismo ritmo ni en todos los sectores económicos ni en todos los ámbitos geográficos. La circulación humana está mucho más restringida que la de los bienes y servicios, y mucho más que la de los capitales: y eso produce desequilibrios evidentes, entre los que hay que citar como los más sangrantes los flujos migratorios hacia la Unión Europea a través del Estrecho de Gibraltar o desde los países ex-comunistas. Y los flujos de capital, que son los que gozan de mayor libertad de movimientos, no utilizan esa libertad para acudir por igual a todos los países: tanto las inversiones directas como sobre todo las indirectas se dirigen exclusivamente allí donde las expectativas de beneficios son más altas. Estos son datos del PNUD de 1999: más del $80 \%$ de la inversión extranjera directa en economías en desarrollo y en transición en los años 90 ha ido sólo a 20 países, y especialmente a China; la quinta parte de la población mundial de los países más ricos disfruta del $82 \%$ de la ampliación del comercio de exportación y del $68 \%$ de la inversión extranjera, en tanto que el quinto inferior cuenta apenas con el $1 \%^{5}$.

Estos movimientos de capitales están condicionados además por la enorme volatilidad de los mercados financieros, lo que explica la retirada masiva de fondos ante la alarma provocada por rumores o previsiones... Los casos de Indonesia y otros países del Sudeste asiático en 1997 o los de Rusia y Brasil en 1998 son bien ilustrativos de otro de los efectos más negativos de la globalización, recientemente denunciado por el citado informe del PNUD: la disminución de la seguridad humana.

Este concepto de seguridad humana fue elaborado y cuantificado por el Informe sobre el desarrollo humano 1994. Supone una revisión del concepto de seguridad de la época de la guerra fría, cuando se equiparaba a la protección de las fronteras frente a amenazas exteriores. En las nuevas condiciones de la humanidad dicho concepto se corrige en una doble dirección: sustituyendo la seguridad territorial por la seguridad de la población y reconociendo que el principal instrumento para conseguir esta

4 Ibid.

5 Programa de las Naciones Unidas para el Desarrollo, Informe sobre desarrollo humano 1999. La mundialización con rostro humano, Nueva York - Madrid 1999, 31. 
seguridad no son los armamentos sino el desarrollo humano ${ }^{6}$.

Pues bien, el Informe de 1999 vuelve sobre la seguridad humana para relacionarla con el proceso de globalización y mostrar cómo le afecta negativamente. La globalización dispar trae, no sólo integración, sino también fragmentación y exclusión, dividiendo a comunidades o pueblos y haciendo aumentar de la inseguridad. La disparidades en el ingreso van en aumento; crece la inseguridad en cuanto al empleo y al ingreso, como consecuencia de la flexibilización de la legislación laboral y de la reestructuración de empresas y las fusiones; la volatilidad financiera acelera los periodos de auge y depresión económicas; el peligro de contagio y amenaza de una recesión a escala mundial aumenta; se abren muchas oportunidades a la delincuencia (especialmente a la delincuencia organizada), en relación con el tráfico de drogas, el comercio ilegal de armas, el tráfico ilícito de mujeres y niñas para la explotación sexual; se difunde de manera alarmante el SIDA (con más de 33 millones de enfermos, el 95\% de los cuales viven en el tercer mundo); se da una peligrosa y compleja interacción entre conflicto y negocios; avanza la degradación ambiental com manifestaciones tan dramáticas como los fenómenos del Niño y de la Niña ${ }^{7}$.

Todo esto significa que la globalización es, por lo menos, un fenómeno ambiguo, y que el juicio ético sobre la misma debe ser circunspecto. Con otras palabras, que no podemos, ni canonizarla, ni demonizarla. Más bien hay que hacer un discernimiento de sus efectos y gestionarla fomentando lo que hay de positivo en ella y controlando sus consecuencias negativas.

Entre los cristianos es mayor la tendencia a demonizarla, pero no sólo entre ellos. El grito, tantas veces recogido en las pantallas de televisión últimamente, de ¡Globalización no! expresa bien la fuerte oposición que encuentra en muchos ambientes. Con todo, no me parece la mejor toma de postura: aun reconociendo que slogans como ese no entran nunca en matices, su abuso puede derivar en dosis excesivas de voluntarismo. Proba-

6 Se identifican así hasta siete ámbitos de la seguridad humana: seguridad económica (ingreso básico asegurado), seguridad alimentaria (acceso a los alimentos básicos), seguridad de la salud, seguridad ambiental (medio físico saludable), seguridad personal (frente a la violencia física en todas sus formas), seguridad de la comunidad (basada en la participación en un grupo, familia, comunidad, organización o grupo racial o étnico), seguridad política (vivir en una sociedad que respete sus derechos humanos fundamentales). Cf. Programa de LAs Naciones Unidas PaRa el DeSARRollo, Informe sobre desarrollo humano 1994, Nueva York 1994, 25.52.

7 Programa de las Naciones Unidas para el Desarrollo, Informe sobre desarrollo humano 1999, I.c., 36-44. 
blemente sería más correcto distinguir dos actitudes: la que reconoce lo que en la globalización hay dehecho inevitable y de proceso incontenible, y la que hace una apuesta decidida (de carácter ético, en el fondo) en favor de la globalización. La primera se fija en el ser, la segunda en el deber ser. La confusión a evitar consistiría en aceptar sin limitaciones la globalización por el hecho de tratarse de un proceso incontenible. Me parece más correcto no negar la realidad de la globalización, pero tampoco entregarse a ella sin condiciones como si todo en ella fuera beneficioso para todos.

La corriente neoliberal, tan en auge actualmente, se acercaría más bien a la segunda de esas dos actitudes: abogaría por un fo mento casi incondicional de la globalización. ¿Qué significa, si no, su insistencia en la liberalización, la desregulación y la integración de los mercados? El éxito actual de esta corriente de pensamiento y de política tiene que ver con la crisis del Estado de bienestar y con la hipertrofia del Estado. Sería inútil ignorar los problemas que el neoliberalismo denuncia por resistencia a aceptar sus soluciones ${ }^{8}$. En este sentido es imprescindible entrar en un diálogo serio con estos autores y abordar dichos problemas con todo el rigor y decisión que están exigiendo. Admitir que el neoliberalismo es la ideología que sirve de legitimación a la globalización no es suficiente para rehuir todo debate con ella. La tarea no es fácil: por eso la he colocado como la primera que se deriva de la constatación de los grandes problemas de la justicia en el futuro inmediato.

\section{2a tarea: como cristianos y como jesuitas, vivir la tensión de ser a la vez ciudadanos y forasteros}

Es corriente en muchos ambientes fuertemente marcados por lo religioso un tipo de discurso muy cargado de grandes principios. Y ocurre, como no podía ser menos, entre los cristianos. J usticia, solidaridad, opción preferencial por los pobres, etc. son propuestas recurrentes que se presentan como un grito alternativo ante los graves conflictos de nuestro mundo. Yo mismo los invocaré más adelante. Pero antes de hacerlo me interesa subrayar esta tensión que he denominado tensión de ser a la vez ciudadanos y forasteros.

El peligro de ese recurso a las grandes ideas es que mete en una dinámica de autoexclusión, abocada no pocas veces a la frustración y al escepticismo

8 Cf. I. CamaCho, Diez preguntas sobre el neoliberalismo, Almogaren n. 23 (diciembre 1998) 4576. 
más radicales. Porque la realidad se encarga de mostrar reiteradamente que no está dispuesta a doblegarse sin más a propuestas tan ideales.

Por otra parte, el cristiano no puede ignorar que el mensaje que tiene encargado transmitir no puede prescindir del Reino de Dios. Sin esta dimensión utópica, que todo ser humano necesita en su vida, la fe cristiana degenera en un moralismo individualista e interesado. Por consiguiente, en el anuncio cristiano, que se hace realidad a través de la vida y de la actividad de los creyentes, la utopía del Reino de Dios es como el horizonte que da el último sentido y la fuente más radical de su esperanza.

Pero un dato incontrovertible de los textos evangélicos y del Nuevo Testamento es que ese Reino a la vez está ya presente entre nosotros y es un don escatológico de Dios (es decir, algo que sólo se nos dará en plenitud más allá de la historia). Esta doble afirmación (ya, pero todavía no) puede ser entendida como una contradicción. No ocurrirá eso si la interpretamos en un sentido dinámico: en nuestra realidad hay como un germen de transformación que hace evolucionar a la humanidad hacia esa utopía del Reino. Pero este no es un germen mágico que actúa independientemente de la acción humana. No es ese el estilo del Dios cristiano, por más que muchas veces unos y otros se empeñen en reducirlo a eso. El Dios cristiano prefiere actuar a través de los humanos que hacerlo directa y hasta espectacularmente.

Por eso es tarea decristiano descubrir todo lo que en estemundo, en laacción de tantos e independientemente de sus convicciones últimas, está en la línea de este proyecto de Dios. Al cristiano le toca descubrirlo y apoyarlo; también promover por su cuenta iniciativas que se orienten hacia este proyecto.

Este compromiso no es fácil de cumplir. Los obstáculos no faltan: unas veces es la pereza de entrar en cuestiones complejas y que parecen desbordar al ciudadano medio; otras, una esperanza mal entendida o una comprensión de la religión demasiado individualista e intimista. El hecho es que con frecuencia se detecta una escasa sensibilidad de los creyentes hacia estos compromisos.

El Concilio Vaticano II dio un fuerte impulso a este compromiso al dedicar una parte de sus esfuerzos a clarificar y revisar la presencia y la acción de la Iglesia en la sociedad. Esta revisión hay que enmarcarla en una marcada sensibilidad hacia la historia, hacia una visión dinámica de la realidad ${ }^{9}$. Por

9 Los capítulos 3o (La actividad humana en el mundo) y 4o (Misión de la Iglesia en el mundo contemporáneo) de la Constitución conciliar Gaudium et spes abordan detenidamente esta cuestión. 
eso cuestiona a aquellos cristianos que pretextando que no tenemos aquí ciudad permanente, pues buscamos la futura, consideran que pueden descuidar las tareas temporales, o a los que piensan que pueden entregarse totalmente a los asuntos temporales como si estos fuesen ajenos del todo a la vida religiosa. $Y$ es que el divorcio entre la fe y la vida diaria de muchos debe ser considerado como uno de los más graves errores de nuestra época ${ }^{10}$.

El mejor antídoto para este divorcio es la definición que el Concilio da de la Iglesia tomando como base la misión de ésta:

La Iglesia es en Cristo como un sacramento o señal e instrumento de la unión íntima con Dios y de la unidad del género humano ${ }^{11}$.

Es necesario detenerse en el concepto teológico de sacramento, que ha sido escogido por el Concilio como el más adecuado para definir la Iglesia. La tradición eclesial de siglos lo había aplicado a los siete conocidos: bautismo, confirmación, eucaristía, etc. Ahora se emplea para expresar lo que es la Iglesia. La tradición teológica acostumbraba a definir el sacramento como signo visible y eficaz: es decir, en él se unen de alguna manera dos realidades que son de distinto nivel, una significante y otra significada. La significante es una realidad presente, pero remite a otra mayor, la significada, al tiempo que la haceya de al gún modo, incipiente y como germinal pero real, verdaderamente presente. No estamos ante un juego de palabras, sino ante una realidad que se vive como tensión entre dos polos. Veamos cómo se aplicaría a la Iglesia.

El significante es la Iglesia misma, en cuanto comunidad total y en cada uno de sus miembros. Lo que ella, o cada uno de sus miembros, debe significar (hacer presente, de una forma efectiva, aunque incompleta) son dos cosas, según expresa el mismo pasaje que estamos comentando: la unión íntima de la humanidad con Dios y de la unidad del género humano. Sólo en el Reino definitivo de Dios (en la utopía del Reino) se vivirá en plenitud esa apertura a Dios y esa fraternidad humana. Entretanto, en este mundo, que camina hacia el Reino, la Iglesia lo anuncia y lo hace realidad de forma incipiente (como signo) mostrando que los seres humanos estamos llamados a abrirnos a Dios y a vivir como hermanos, que merece la pena aunar esfuerzos para caminar en esa doble dirección. La historia humana nunca experimentará en plenitud la utopía del Reino, pero esa utopía será

10 Concilio Vaticano II, Constitución pastoral sobre la Iglesia en el mundo moderno, Gaudium et spes n. 43.

11 Concilio Vaticano II, Constitución dogmática sobre la Iglesia, Lumen gentium, n. 1. 
siempre el horizonte y el motor de la historia, cuando se vive desde la fe.

En resumen, esta presentación de la Iglesia recupera la importancia que en ella tiene su misión de estar presente en el mundo, y de estar presente de una manera muy concreta: no como instancia de poder, que sirve para estructurar a la sociedad desde arriba (cosa que ocurrió en otro tiempo y a la que se aspiró en épocas posteriores), sino como testimonio y como presencia. Esta interpretación de lo que es la Iglesia, actualizada y profundizada por el Vaticano II, abrió una línea fecunda para la presencia de los cristianos en la sociedad, que se desarrolla en medio de no pocos conflictos y perplejidades intraeclesiales, pero también en confrontación con una sociedad marcada por cambios elocuentes. Entre ellos interesa en este momento subrayar una conciencia cada vez más difundida de las diferencias económicas y sociales de nuestro mundo, más lacerantes en un periodo de rápido crecimiento económico y notables expectativas de desarrollo.

Pocos años más tarde un nuevo documento oficial de la Iglesia -ahora del sínodo universal de obispos, celebrado en 1971- volvía sobre el alcance de esta misión, pero concretándolo ahora precisamente a la lucha por un mundo más justo:

La acción en favor de la justicia y la participación en la transformación del mundo se nos presenta claramente como una dimensión constitutiva de la predicación del evangelio, es decir, de la misión de la Iglesia para la redención del género humano y la liberación de toda situación opresiva ${ }^{12}$.

Aquí ya no cabe duda de que transformar este mundo, no sólo es tarea propia de la Iglesia, sino dimensión esencial a su misión (constitutiva de ésta). Claro que este texto no hay que leerlo en clave clerical, como si todo lo que afirma de la Iglesia se afirmara en primer término de los obispos y clérigos en general: entonces nos enredamos en cuestiones tales como el compromiso político y social de los clérigos, que tantas energías consumió en tiempos pasados. Leída, en cambio, en la clave de la eclesiología del Vaticano II -para la que la Iglesia es, ante todo, la comunidad del pueblo de Dios, laicos y pastores-, se entiende que esta misión la desarrolla el conjunto de sus miembros, y además de forma complementaria, cada uno según su condición y cualidades y según el lugar que ocupa en la sociedad.

Por su parte, la Compañía de Jesús, en su Congregación General 32, celebrada en 1974-75, -es decir, en el contexto marcado por el citado sínodo

12 Sínodo Universal de Obispos de 1971, La justicia en el mundo, Introducción. 
y por el que le siguió en 1974, que tuvo como tema central la evangelizaciónreformuló desde estas nuevas directrices eclesiales su propia misión, definiéndola ahora como servicio de la fe y promoción de la justicia, dos dimensiones indisolublemente unidas:

La misión de la Compañía de Jesús hoy es el servicio de la fe, del que la promoción de la justicia constituye una exigencia absoluta, en cuanto forma parte de la reconciliación de los hombres exigida por la reconciliación de ellos mismos con Dios ${ }^{13}$.

La intuición de fondo es la misma: que el anuncio del Evangelio debe superar ciertas limitaciones que arrastra al menos desde toda la época moderna. Estas limitaciones van en una doble dirección y suponen un doble reduccionismo: a) apuntar a una salvación individual (por tanto, ajena a lo que ocurre en el mundo y en la sociedad); b) remitir esa salvación al más allá de la historia (por tanto, lo que ocurra en la historia es indiferente respecto a su final y nada tiene que ver con lo que Dios promete para ese momento). Lo que ahora se propone es salvar esa ruptura tan radical entre individuo y sociedad, así como entre el presente humano y el futuro (escatológico) de Dios. Se establece entonces una cierta continuidad entre presente y futuro, entre historia y utopía final, de forma que el proceso histórico puede encaminarse hacia esa utopía o desviarse de ella y es a los humanos a quienes corresponde encaminarla en esa dirección.

Viniendo más a lo concreto, la actividad del creyente en el mundo debe ser enfocada y vivida como colaboración a este proceso que hace avanzar al mundo hacia la apertura a la trascendencia y hacia la fraternidad en una tensión siempre inacabada.

Pero esta tensión no es fácil de mantener: el equilibrio entre vivir la utopía del Reino y el compromiso de transformación de la sociedad es tan inestable que siempre amenaza con romperse por un lado o por otro. Cabe refugiarse en la utopía del Reino desentendiéndose en consecuencia de este mundo; pero cabe también implicarse de tal modo en los problemas de cada día que se termine por perder el horizonte de la utopía.

Mantener ese equilibrio es otra de las grandes tareas del cristiano en un mundo globalizado. La globalización nos remite a algo tan cristiano, en principio, como la universalidad. Pero esta universalidad sabemos que está cargada de ambigüedades. Por eso la Iglesia, y cada uno de sus miembros, está llamada a situarse en el corazón mismo de estos procesos con el

13 Congregación General 32, Decreto 4: Nuestra misión hoy, n. 2. 
compromiso de orientarlos hacia cotas más altas de humanización para todos, teniendo como horizonte esa fraternidad universal.

Esta tensión entre el ya del tiempo de Dios, que se inicia en Cristo y relativiza absolutamente toda estructura social, y el todavía no de la espera en el triunfo definitivo de Cristo, puede expresarse como la dialéctica del que se siente a la vez ciudadano y forastero:

La pregunta sobre el cómo de la relación Iglesia-mundo sigue abierta; no hay una respuesta sencilla y universal. La perspectiva escatológica nos obliga a vivir en una perpetua tensión entre sectarismo y aculturación (pérdida de identidad en el proceso de inculturación). De hecho, silenciar la crítica que viene de los movimientos proféticos podría llevar a la Iglesia a ligarse excesivamente a los poderes políticos. Pero subrayar en exceso la especificidad de la vida cristiana haría imposible la misión de evangelizar la cultura y el mundo. La tensión nos obliga a ser ciudadanos sin perder la distancia del que se sabe forastero ${ }^{14}$.

Esta doble condición profundamente vivida lleva a no minusvalorar los esfuerzos de muchos que también viven el afán por humanizar nuestro mundo aunque no lo hagan con motivaciones cristianas ni siquiera religiosas, porque no podemos romper los canales de comunicación con la sociedad ni olvidar nunca que Dios actúa no sólo dentro de la comunidad eclesial, sino en todo lugar ${ }^{15}$.

En tiempos muchos más antiguos ya se empleó esta contraposición de ciudadanos y forasteros para expresar la forma característica de los cristianos en la sociedad. Véase este testimonio, que suele datarse a mediados del siglo II. Está tomado de la Carta a Diogneto:

Los cristianos no se distinguen de los demás hombres ni por su tierra, ni por su habla, ni por sus costumbres. Porque ni habitan ciudades exclusivas suyas, ni hablan una lengua extraña, ni llevan un género de vida aparte de los demás. A la verdad, esta doctrina no ha sido por ellos inventada gracias al talento y especulación de hombres curiosos, ni profesan, como otros hacen, una enseñanza humana; sino que, habitando ciudades griegas o bárbaras, según la suerte que a cada uno le cupo, y adaptándose en vestido, comida y demás género de vida a los usos y costumbres de cada país, dan muestra de un tenor de peculiar conducta, admirable y, por confesión de todos, sorprendente. Habitan sus propias patrias, pero como forasteros; toman parte en todo como ciudadanos y todo lo soportan como extranjeros; toda tierra extraña es para ellos patria, y toda patria, tierra extraña ${ }^{16}$.

14 P. Coduras, Voluntarios: discípulos y ciudadanos, Barcelona, Cristianisme i Justícia, 1995 (Cuadernos 68) 18.

15 Ibid.

16 Carta a Diogneto, cap. 5. 
Como síntesis conclusiva de este punto me permito reproducir un pasaje de la citada Congregación General 32 de la Compañía de Jesús, en que se pretende definir en qué consistela justicia por la que los jesuitas (también los cristianos) deberían luchar para mantener este equilibrio y esta tensión. No es otra que

...la perfecta justicia del Evangelio, que dispone no sólo a reconocer y respetar los derechos y la dignidad de todos, especialmente de los más pequeños y débiles, sino, aún más, a promoverlos eficazmente y a abrirse a toda miseria, aun la del extraño o enemigo, hasta el perdón de las ofensas y la victoria sobre las enemistades por la reconciliación ${ }^{17}$.

\section{3a tarea: apostar por la solidaridad como clave de un sistema nuevo de valores}

Al formular esta tercera tarea reconozco que me estoy metiendo ya en el terreno de la segunda ponencia de este encuentro: Qué talante, qué cultura y qué fe para la transformación social. Pero es que la relación entre ambas ponencias es imprescindible si queremos comprender la verdadera raíz y la justificación última de estos problemas de la justicia que nos ocupan. Esta raíz no es otra que los sistemas de valores dominantes en nuestra sociedad, los cuales sirven de justificación, tanto a comportamientos individuales como a instituciones sociales.

En este punto voy a aprovechar la aportación de Juan Pablo II en su encíclica de 1987 sobre el desarrollo de los pueblos: la Sollicitudo rei socialis. En ella, no sólo se reconoce que la causa última de las diferencias crecientes en nuestro mundo está en el sistema de valores dominantes, sino que se concreta cuál es la clave de ese sistema y cuál podría ser el eje de un sistema de valores alternativo.

A la primera cuestión no voy a dedicarle mucho tiempo, porque me parece más obvia: que las instituciones sociales y los comportamientos individuales se rigen por determinados valores, los cuales son asumidos de forma natural y casi inconsciente por todos. Cuando hablo de sistema de valores quiero referirme, no a la opción por unos valores en sí mismos considerados, sino a su jerarquización según una escala de prioridades. Con un ejemplo se verá mejor. No se trata de discutir si la libertad o la igualdad son valores en sí mismos: en esto, todo el mundo estará de acuerdo. Se trata, más bien, de

17 Congregación General 32, Decreto 4, n. 18. Cf. también: Congregación General 34, Decreto 3, n. 4. 
determinar qué puesto ocupan en la escala de valores, o ante qué otros valores cederían en caso de conflicto. Dicho de otra manera: cuando en una situación concreta la realización, por ejemplo, de la libertad entre en conflicto con la realización de la igualdad, ¿cuál de ellos cede ante el otro?

La segunda cuestión queformulaba pretende discutir el sistema de valores dominante en nuestro mundo y sus posibles alternativas.

J uan Pablo II hace este análisis en términos teológicos, pero sus reflexiones admiten, sin que tengan que ser forzadas artificialmente, una lectura en términos éticos. Él habla de estructuras de pecado.

Para entender la definición que se da de éstas hay que tener en cuenta ciertas preocupaciones teológicas y pastorales de estos últimos decenios en relación con la conciencia de pecado. Ante el hecho de una pérdida creciente de esta conciencia de pecado, se ha producido un fuerte debate en torno a categorías como pecado social o pecado estructural: mientras unos insistían en estos nuevos conceptos como imprescindibles para comprender la realidad del mal ético en nuestro mundo, que no puede reducirse a comportamientos individuales, otros veían en este enfoque un estímulo más para reducir la conciencia de pecado.

J uan Pablo II, a pesar de no ser ajeno a dichas preocupaciones, considera insoslayable esa dimensión ética de la realidad que va más allá de la acción de los individuos. Implícitamente reconoce que todas las injusticias y desigualdades actuales no se pueden explicar invocando sólo actos personales. La expresión que escoge para designar esta realidad es la de estructuras de pecado. Ahora bien, en la definición que da de ellas es fácil percibir su preocupación por presentarlas de forma que no contribuyan a diluir más aún la responsabilidad de las personas.

Con estas observaciones véanse los términos concretos en que Juan Pablo Il define las estructuras de pecado. Parte del análisis previo, que le ha llevado a ver en la división del mundo en bloques (estamos todavía en 1987) la raíz de las diferencias crecientes entre pueblos:

\footnotetext{
Por tanto, hay que destacar que un mundo dividido en bloques, presididos a su vez por ideologías rígidas donde, en lugar de la interdependencia y la solidaridad, dominan diferentes formas de imperialismo, no es más que un mundo sometido a estructuras de pecado (...)

Si la situación actual hay que atribuirla a dificultades de diversa índole, se debe hablar de "estructuras de pecado", las cuales - como ya he dicho en la Exhortación Apostólica "Reconciliatio et paenitentia"- se fundan en el pecado personal y, por consiguiente,
} 
están unidas siempre a actos concretos de las personas, que las introducen, y hacen difícil su eliminación. Y así estas mismas estructuras se refuerzan, se difunden y son fuente de otros pecados, condicionando la conducta de los hombres ${ }^{18}$.

Lo más destacado de este texto es la relación recíproca entre pecado personal y estructuras de pecado: el origen de éstas está en la acumulación de innumerables pecados personales; pero dichas estructuras, una vez consolidadas, contribuyen a que las personas actúen de acuerdo con ellas y cometan así nuevos pecados personales. En términos éticos: los valores dominantes en una sociedad (o, mejor en este caso, los antivalores) llegan a ser dominantes por la acumulación de muchos comportamientos inspirados por ellos; de este modo, terminan por hacerse tan familiares a todos que actuamos con total naturalidad (y casi inconscientemente) en función de ellos.

Pero ¿cuáles son concretamente esos valores dominantes o esas estructuras de pecado? J uan Pablo II responde un poco más adelante:

A este análisis genérico de orden religioso se pueden añadir algunas consideraciones particulares para indicar que, entre las opiniones y actitudes opuestas la voluntad divina y al bien del prójimo y las "estructuras" que conllevan, dos parecen ser las más características: el afán de ganancia exclusiva, por una parte; y por otra, la sed de poder, con el propósito de imponer a los demás la propia voluntad. A cada una de estas actitudes podría añadirse, para caracterizarlas aun mejor, la expresión: "a cualquier precio" (...).

Ambas actitudes, aunque sean de por sí separables y cada una pueda darse sin la otra, se encuentran -en el panorama que tenemos ante nuestros ojos- indisolublemente unidas, tanto si predomina la una como la otra ${ }^{19}$.

J uan Pablo II se refiere a dos actitudes, que son en el fondo dos valores: el afán de ganancia y la sed de poder. Y las caracteriza con estos dos rasgos: absolutizadas (a cualquier precio, es decir, por encima de todo) e inseparables (indisolublemente unidas).

Hasta ahí el texto de la encíclica. Pero podemos avanzar en la reflexión a partir de ahí. ¿Cabría, entonces, identificar estas dos actitudes con la competitividad, como valor que hoy se erige en la cima de todo sistema de valores y en la clave que explica tantos comportamientos individuales y tantas dinámicas sociales? Lo que sería criticable en ella no es tanto el valor en sí (ciertas dosis de competitividad son beneficiosas, para las personas y para el conjunto de la sociedad) como su tendencia a colocarse por encima de todos los demás.

\footnotetext{
18 J Uan Pablo II, Sollicitudo rei socialis, 36.

19 Ibid., 37.
} 
Al llegar aquí no está de más recordar que la denuncia que hace J uan Pablo II de esta realidad parte de la constatación de esa dinámica de desigualdades que caracteriza a nuestro mundo:

(...) junto a las miserias del subdesarrollo, que son intolerables, nos encontramos con una especie de superdesarrollo, igualmente inaceptable porque, como el primero, es contrario al bien y a la felicidad auténtica (...)

Este es pues el cuadro: están aquellos -los pocos que poseen mucho- que no llegan verdaderamente a "ser", porque, por una inversión de la jerarquía de los valores, se encuentran impedidos por el culto del "tener"; y están los otros - los muchos que poseen poco o nada- Ios cuales no consiguen realizar su vocación humana fundamental al carecer de los bienes indispensables ${ }^{20}$.

Frente esta realidad, que es denunciada en sus manifestaciones y en el sistema de valores que la alimenta, Juan Pablo II propone como alternativa la solidaridad. Estaríamos ante un nuevo sistema de valores cuyo eje fuera la solidaridad. Esta propuesta me parece extraordinariamente fecunda si se la trata con cierta cautela: en caso contrario, corre el peligro de caer en la absoluta esterilidad.

La solidaridad es una palabra que hoy se ha puesto de moda ${ }^{21}$. Como ocurre en tales casos, se convierte en recurso tan fácil para responder a mil situaciones diversas, que termina por vaciarse de todo contenido. La encíclica que estamos comentando hace un esfuerzo encomiable por aclarar el sentid o y el alcance dela solidaridad. Merece la pena que le dediquemos unos párrafos.

En sus reflexiones cabe distinguir tres niveles: el de análisis de la realidad, el del discurso ético y el del discurso teológico. Los dos primeros se relacionan así en el siguiente pasaje:

Ante todo se trata de la interdependencia percibida como sistema determinante de relaciones en el mundo actual, en sus aspectos económico, cultural, político y religioso, y asumida como categoría moral. Cuando la interdependencia es reconocida así, su correspondiente respuesta, como actitud moral y social, y como "virtud", es la solidaridad. Esta no es, pues, un sentimiento superficial por los males de tantas personas, cercanas o lejanas. Al contrario, es la determinación firme y perseverante de

20 Ibid., 28.

21 Para el tema de la solidaridad puede verse, desde una postura filosófico-política, V. CAmps,

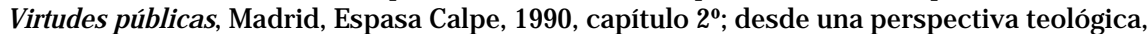
M. VIDAL, Para comprender la solidaridad, Estella (Navarra), Verbo Divino, 1996, especialmente los capítulos 30 y 5‥ Cf. también J. García Roca, Solidaridad y voluntariado, Santander, Sal Terrae, 1994, capítulos 50 y 60. 
empeñarse por el bien común; es decir, por el bien de todos y cada uno, para que todos seamos verdaderamente responsables de todos 22.

En efecto, la solidaridad como actitud ética es la respuesta más adecuada a la situación actual, que la encíclica sintetiza como interdependencia. Dicha interdependencia no es en el fondo algo que difiera mucho de lo que se conoce como globalización, término este cuyo uso aún no se había generalizado en 1987.

Pero lo más destacable del pasaje citado es la definición que da de solidaridad. Implícitamente hay en él una contraposición entre lo que otros han Ilamado solidaridad blanda y solidaridad fuerte. La primera sería ésa que se queda en un sentimiento superficial, es decir, que no afecta a la vida del sujeto. La segunda, en cambio, consistiría en vivir con todas sus consecuencias el que todos seamos responsables de todos. Parafraseando a J uan Pablo II, si todos somos dependientes de todos (un hecho), es preciso que todos seamos responsables de todos (un imperativo ético que deriva del hecho anterior).

Esta forma de vivir la solidaridad quiebra la lógica de la competitividad, y en este sentido es base para una alternativa a aquélla. La competitividad supone que el otro (los otros) es por principio un enemigo potencial. La vida de cada uno se construye en lucha con los demás, aunque esta lucha se lleve a cabo de la forma más exquisita según todas las normas del juego limpio. Psicológicamente la imagen del competidor (con el que se disputa la consecución de algo) es difícil de eludir. La solidaridad supone ver en el otro, no al que me disputa algo, sino aquel con el que se comparte algo (o todo). Las energías de uno y otro no están en confrontación, sino en convergencia.

Todo esto puede sonar a una pura exhortación, más orientada a las buenas intenciones que a una operatividad efectiva. Para evitar este peligro, tan real por otra parte, habría que añadir que la solidaridad ha de ser entendida, no sólo como virtud, sino además como principio de organización de la sociedad $^{23}$. Es decir, su función no se limita a orientar los comportamientos (no ya los sentimientos...) individuales, sino que deberá llegar a inspirar las formas de organización de la sociedad a todos los niveles. Dos aplicaciones concretas ayudarán a comprender el alcance de esta propuesta.

22 Ibid., 38.

23 Cf. sobre este punto: M. VIDAL, Ética de la solidaridad, Moralia 14 (1992) 347-362. 
Citemos en primer lugar, al moderno Estado de bienestar, el cual respondía ya a este enfoque. Lo nuevo en él era precisamente lo que podríamos llamar una institucionalización de la solidaridad. En virtud de la misma, las necesidades de una parte de la población eran cubiertas con recursos de otros. La crisis actual de dicho modelo abre no pocos interrogantes. Pero uno de los más acuciantes es el siguiente: ¿no sería que nos habíamos acostumbrado a una solidaridad poco costosa (mantenida gracias a un proceso sostenido de crecimiento económico, que hacía poco perceptibles sus costes) y que la crisis nos está confrontando por primera vez a los costes de esa solidaridad? Por esta vía de análisis se intuye entonces algo muy importante: que las estructuras institucionales de solidaridad no se mantienen a la larga si no están apoyadas por una solidaridad asumida como virtud y como actitud humana por todos los ciudadanos... Esto nos remite a algo ya dicho más arriba: que las instituciones sociales son legitimadas o cuestionadas desde los sistemas de valores dominantes en la sociedad.

Si pasamos ahora al nivel planetario, reaparece la demanda desolidaridad. La conciencia de que los grandes problemas de la humanidad no pueden ser resueltos ya sino desde la cooperación de todos van ganando terreno en la opinión pública mundial, entre los gobernantes de los países y en los organismos internacionales. La sucesión de conferencias mundiales organizadas por Naciones Unidas desde la de Río de J aneiro en 1992 (sobre Medio ambiente y desarrollo) son una muestra de ello. Recuérdese que estas conferencias no son meros congresos, que reúnen a especialistas, sino foros donde se dan cita los responsables de los gobiernos. Desgraciadamente sus resultados han sido escasos. Pero esto no puede ocultarnos que dichas conferencias se convocan desde un presupuesto nuevo: esa necesidad de abordar desde la corresponsabilidad y la cooperación problemas que ya no se localizan dentro de las fronteras territoriales de un Estado u otro. ¿No es esto una nueva expresión de la solidaridad, por mucho que se considere raquítica en sus resultados y hasta interesada en sus motivaciones?

Sin embargo, Juan Pablo II no se queda en esta consideración ética de la solidaridad. Como hace en otras ocasiones, subraya el plus cristiano de lo que tiene pleno sentido desde una perspectiva humana. Por eso habla de las dimensiones cristianas de la solidaridad:

(...) A la luz de la fe, la solidaridad tiende a superarse a sí misma, al revestirse de las dimensiones específicamente cristianas de gratuidad total, perdón y reconciliación. Entonces el prójimo no es solamente un ser humano con sus derechos y su igualdad fundamental con todos, sino que se convierte en la imagen viva de Dios Padre, 
rescatada por la sangre de Jesucristo y puesta bajo la acción permanente del Espíritu Santo. Por tanto, debe ser amado, aunque sea enemigo, con el mismo amor con que le ama el Señor, y por él se debe estar dispuestos al sacrificio, incluso extremo: “dar la vida por los hermanos" (cf. 1 In 3,16) ${ }^{24}$.

Gratuidad total, perdón y reconciliación son esas dimensiones que el cristiano puede añadir a la solidaridad con vistas a hacerla más profunda y rica. De nuevo aquí estamos en la dinámica de ser a la vez ciudadanos y forasteros: no se pretende negar los esfuerzos solidarios que surgen de la condición ciudadana de tantos, pero tampoco se puede excluir la oportunidad de hacer presente la utopía del Reino de Dios, que, como horizonte genérico, se concreta ahora en nuevas dimensiones para la solidaridad.

\section{A modo de conclusión}

Sólo me queda, para terminar, insistir en lo que decía al principio: que los grandes problemas de la justicia hoy no pueden abordarse sólo desde fórmulas técnicas queaporten soluciones. Esas fórmulas nunca llegarán a ser articuladas y ni siquiera pensadas si falta una sensibilidad básica o una sintonía con determinados valores. Eso es lo que estas páginas querían poner de relieve. Para ello he formulado tres retos o tareas: comprender la globalización en todas sus dimensiones y comprender la ideología que le sirve de legitimación; vivir, en cuanto cristianos y en cuanto jesuitas, la tensión de ser a la vez ciudadanos y forasteros; apostar por la solidaridad como clave de un sistema nuevo de valores.

Estas propuestas están explícitamente hechas para creyentes, pero tienen validez ética entre todos aquellos que son sensibles a las injusticias de nuestro mundo. No pretenden contraponer de forma excluyente lo cristiano a lo meramente humano, sino presentar lo cristiano como enriquecimiento y radicalización de lo humano.

Por último, moverse en el terreno de los sistema de valores no significa despreciar el esfuerzo por buscar soluciones técnicas a los problemas. Eso llevaría a un voluntarismo bastante infecundo. Apostar por determinados valores no es cortocircuitar el camino tortuoso de lo técnico y lo concreto, sino ofrecer estímulos y un horizonte de sentido para avanzar por él sin desfallecer.

24 Juan Pablo II, Sollicitudo rei socialis, 40. 